\title{
Cinnamaldehyde/chemotherapeutic agents interaction and drug-metabolizing genes in colorectal cancer
}

\author{
CHEN YU ${ }^{1}$, SHEN-LIN LIU ${ }^{2}$, MING-HAO $\mathrm{QI}^{3}$ and XI ZOU ${ }^{4}$ \\ ${ }^{1}$ First Clinical Medical College, Nanjing University of Chinese Medicine, Nanjing, Jiangsu 210046; \\ ${ }^{2}$ Senior Expert Consultation Center; ${ }^{3}$ National Clinical Research Base of Traditional Chinese Medicine; \\ ${ }^{4}$ Department of Oncology, Affiliated Hospital of Nanjing University of Chinese Medicine, Nanjing, Jiangsu 210029, P.R. China
}

Received June 9, 2013; Accepted November 20, 2013

DOI: $10.3892 / \mathrm{mmr} .2013 .1830$

\begin{abstract}
Cinnamaldehyde is an active monomer isolated from the stem bark of Cinnamomum cassia, a traditional oriental medicinal herb, which is known to possess marked antitumor effects in vitro and in vivo. The aim of the present study was to examine the potential advantages of using cinnamaldehyde in combination with chemotherapeutic agents commonly used in colorectal carcinoma (CRC) therapy, as well as to investigate the effect of cinnamaldehyde on chemotherapeutic-associated gene expression. The synergistic interaction of cinnamaldehyde and chemotherapeutic agents on human CRC HT-29 and LoVo cells was evaluated using the combination index $(\mathrm{CI})$ method. The double staining with Annexin V conjugated to fluorescein-isothiocyanate and phosphatidylserine was employed for apoptosis detection. The expression of drug-metabolizing genes, including excision repair cross-complementing 1 (ERCC1), orotate phosphoribosyltransferase (OPRT), thymidylate synthase (TS), breast cancer susceptibility gene 1 (BRCA1) and topoisomerase 1 (TOPO1), all in HT-29 and LoVo cells, with or without the addition of cinnamaldehyde, was examined by quantitative polymerase chain reaction (PCR). Cinnamaldehyde had a synergistic effect on the chemotherapeutic agents cytotoxicity in HT-29 and LoVo cells. In addition, cinnamaldehyde suppressed BRCA1, TOPO1, ERCC1 and TS mRNA expression, except for OPRT expression, which was markedly upregulated. Our findings indicate that cinnamaldehyde appears to be a promising candidate as an adjuvant in combination therapy with 5-fluorouracil (5-FU) and oxaliplatin (OXA), two chemotherapeutic agents used in CRC treatment. The possible mechanisms of its action may involve the regulation of drug-metabolizing genes.
\end{abstract}

Correspondence to: Professor Shen-Lin Liu, Senior Expert Consultation Center, Affiliated Hospital of Nanjing University of Chinese Medicine, No. 155 Hanzhong Road, Nanjing, Jiangsu 210029, P.R. China

E-mail: 1s186618555@sina.com

Key words: colorectal cancer, cinnamaldehyde, chemotherapeutic agents, synergistic interaction, drug-metabolizing genes

\section{Introduction}

Colorectal carcinoma (CRC) is one of the most prevalent types of cancer in Western countries $(1,2)$ and the third most common cancer worldwide, with an incidence of approximately one million cases and 500,000 mortalities annually $(3,4)$. Despite huge efforts to resolve the molecular basis of this disease, it remains a therapeutic challenge for oncologists due to its often late detection and poor prognosis. Currently, there are no standardized treatment protocols, nevertheless the increasing number of active cytotoxic drugs and targeted therapies have placed clinicians in front of a broad spectrum of therapeutic options (5-9). Oxaliplatin (OXA), 5-fluorouracil (5-FU) and irinotecan (IRI) are presently the mainstay of chemotherapeutic treatment for CRC, and OXA/5-FU/leucovorin (LV; FOLFOX) and folinic acid [(FOL)/5-FU/IRI; FOLFIRI)] are considered the standard treatment regimens for advanced CRC $(5,10)$. However, the positive response rate of patients to therapy remains $<40 \%(11,12)$. Hence, better systemic therapies are needed to decrease side effects and improve the clinical outcomes of patients with CRC.

Despite recent advances in chemotherapeutic treatment, the five-year survival rate for CRC remains relatively poor (13), with a median survival of 25 months $(14,15)$. In addition, antineoplastic agents often achieve antitumor activity at the expense of a practically unacceptable toxicity. OXA, 5-FU and IRI have different mechanisms of action and different toxicity profiles (16). Over the years various attempts have been made to improve the objective response rate to chemotherapy, including different chemotherapeutic agents and their combinations, as well as the use of distinct adjuvants. In general, the rationale for the combination of two or more therapeutic agents is to achieve lower drug doses, reduce toxicity and minimize or delay treatment resistance.

Several compounds traditionally used in Chinese medicine have previously been used as an adjuvant to chemotherapy, demonstrating positive effects, specifically in the sensitization of the last one (17).

Cinnamomum cassia Presl. (Lauraceae) has been traditionally used in Chinese medicine to treat dyspepsia, gastritis, blood circulation disturbances and inflammatory diseases (18). Cinnamaldehyde is the main bioactive compo- 
nent of cinnamon bark oil that has been widely used as a food flavoring agent. Several biological activities, including peripheral vasodilatory effect, antitumor, antifungal, cytotoxic and mutagenic/anti-mutagenic activities, have been associated with cinnamaldehyde (19-22).

In our previous studies, we demonstrated that cinnamaldehyde is able to exhibit several biological effects, including antiangiogenic effects (23) as well as chemopreventive (24) and anti-inflammatory activities (25). Other previous studies demonstrated that cinnamaldehyde induced apoptosis in a variety of tumor cell lines, including two human leukemia cell lines HL-60 and K562 $(26,27)$ and human hepatoma PLC/PRF/5 cells (28). Furthermore, cinnamaldehyde also exhibited antiproliferative activity in human colon-derived SW620 and human mammary-derived MCF-7 carcinoma cells (29).

However, despite the various biological activities of cinnamaldehyde, its potential role in cancer therapy has not been clearly addressed. In addition, whether the combination of cinnamaldehyde and chemotherapeutic agents may possibly result in a useful synergistic interaction against CRC cells has not been examined thus far.

Therefore, in order to elucidate the mechanisms possibly involved in the interaction between the cinnamaldehyde and chemotherapeutic agents, we examined the effect of this treatment on apoptosis as well as the expression of drug-metabolizing genes in CRC cells.

\section{Materials and methods}

Drugs. Cinnamaldehyde (molecular formula, $\mathrm{C}_{9} \mathrm{H}_{8} \mathrm{O}$ ) was obtained as a powder with a purity of $98.6 \%$ from the National Institutes for Food and Drug Control (Beijing, China). OXA, 5-FU and IRI were supplied from Jiangsu Hengrui Medicine Company (Jiangsu, China). All reagents were prepared in complete culture medium immediately prior to their use in vitro. 3-(4,5-Dimethylthiazol-2-yl)-2,5-diphenyltetrazolium bromide (MTT) was purchased from Sigma Chemical Company (St. Louis, MO, USA). Annexin V conjugated to fluorescein-isothiocyanate (Annexin V-FITC) Apoptosis Detection kit was purchased from Invitrogen Life Technologies (Carlsbad, CA, USA). All other chemicals used were of the highest purity grade available.

Cell culture. The human well-differentiated colon adenocarcinoma cell line HT-29 and poorly differentiated colon adenocarcinoma cell line LoVo were obtained from Shanghai Institute of Cell Biology (Shanghai, China). All cell lines were propagated in RPMI-1640 medium (Gibco-BRL, Grand Island, New York, USA), supplemented with $10 \%$ bovine serum albumin, penicillin (100 U/ml)-streptomycin $(100 \mathrm{mg} / \mathrm{ml})$, pyruvate, glutamine and insulin at $37^{\circ} \mathrm{C}$ in a water-saturated atmosphere with $5 \% \mathrm{CO}_{2}$.

Measurement of the $I C_{50}$ (half maximal inhibitory concentration) for cinnamaldehyde and chemotherapeutic agents. Tumor cells in log-phase were trypsinized and seeded at $2 \times 10^{3}$ cells per well into 96 -well plates and allowed to attach overnight. The next day, the medium in each well was replaced with fresh medium or medium with various concentrations of drugs in at least five replicate wells and incubated for $48 \mathrm{~h}$. The medium-containing drug was decanted and the $\mathrm{IC}_{50}$ doses for each drug were determined by an MTT assay. The $\mathrm{IC}_{50}$ was defined as the concentration required for $50 \%$ inhibition of cell growth. In each experimental plate, 10 wells containing drug-free medium were used as a control and each experiment was repeated at least three times.

Determination of synergism and antagonism. Subconfluent CRC cells were seeded at $2 \times 10^{3}$ cells per well in 96-well plates. Drugs were added either concomitantly or sequentially with six different concentrations of the single agent and six different concentrations of the two agents at their fixed ratio based on their respective individual $\mathrm{IC}_{50}$ values for $48 \mathrm{~h}$. The fractional inhibition of cell proliferation was calculated by comparison to control cultures. Dose-response curves were obtained for each drug and for multiple dilutions of two drugs fixed-ratio combinations. Median effect analysis using the combination index (CI) method of Chou and Talalay (30) was employed to determine the nature of the interaction observed between cinnamaldehyde and chemotherapeutic agents. The CI was defined by the following equation, in which (Dx) 1 and (Dx) 2 are, respectively, the concentrations for D1 (CI) and D2 (chemotherapeutic agent) alone that give $\mathrm{x} \%$ inhibition, whereas (D)1 and (D)2 in the numerator are, respectively, the concentrations of cinnamaldehyde and another drug that produces the identical level of effect in combination.

$$
\mathrm{CI}=\frac{(\mathrm{D}) 1}{(\mathrm{Dx}) 1}+\frac{(\mathrm{D}) 2}{(\mathrm{Dx}) 2}+\alpha \frac{(\mathrm{D}) 1(\mathrm{D}) 2}{(\mathrm{Dx}) 1(\mathrm{Dx}) 2}
$$

The alpha value was determined as follows: $\alpha=0$ when drugs were mutually exclusive (i.e., with similar modes of action), while $\alpha=1$ when they were mutually non-exclusive (i.e., with independent modes of action). Finally, the CI values were defined as follows: $\mathrm{CI}>1$ indicated antagonism, $\mathrm{CI}<1$ indicated synergy and $\mathrm{CI}=1$ indicated additivity. Each $\mathrm{CI}$ ratio was the mean value derived from at least three independent experiments.

Cytotoxicity assay. In vitro drug-induced cytotoxic effects were measured by an MTT assay (31). Briefly, following drug treatment, one-tenth volume of MTT was added to each well and the plate was further incubated at $37^{\circ} \mathrm{C}$ for $4 \mathrm{~h}$. To solubilize the MTT-formazan product following the removal of the medium, $200 \mu 1$ of dimethyl sulfoxide was added to each well. Absorbance at $570 \mathrm{~nm}$ was measured with a multiwell spectrophotometer (BioTek Instruments, Inc., Winooski, VT, USA). Growth inhibition was calculated as a percentage of the untreated controls, which were not exposed to drugs.

Apoptosis assay. For the apoptosis assay, cells were cultured in a $60 \mathrm{~mm}$ Petri dish and allowed to grow to confluency. HT-29 cells were treated with $5 \mu \mathrm{g} / \mathrm{ml}$ cinnamaldehyde and $0.625 \mu \mathrm{g} / \mathrm{ml} 5-\mathrm{FU}$ and $6.25 \mu \mathrm{g} / \mathrm{ml} \mathrm{OXA}$ and $2.5 \mu \mathrm{g} / \mathrm{ml}$ cinnamaldehyde. LoVo cells were treated with $2.5 \mu \mathrm{g} / \mathrm{ml} 5-\mathrm{FU}$ and $2.5 \mu \mathrm{g} / \mathrm{ml}$ cinnamaldehyde. Next, they were exposed to cinnamaldehyde and anticancer drugs added either individually or in combination for $48 \mathrm{~h}$. Subsequently, cells were collected and incubated with Annexin V-FITC (Bender MedSystems, 
San Diego, CA, USA) for determining surface exposure of phosphatidylserine (PI) in apoptotic cells; the results were compared with those of untreated control cells. Analyses were performed with a FACS Scan flow cytometer (BectonDickinson, Franklin Lakes, NJ, USA).

Quantitative RT-PCR. LoVo and HT-29 cells were seeded on 6 -well plates at $5 \times 10^{5}$ cells $/ \mathrm{ml}$ concentration and treated with cinnamaldehyde at its $\mathrm{IC}_{50}$ value for $48 \mathrm{~h}$. Furthermore, cells were harvested with trypsin, washed with phosphate-buffered saline and collected by centrifugation at $500 \mathrm{x}$ g for $5 \mathrm{~min}$. Total RNA was extracted using TRIzol reagent (Invitrogen Life Technologies) following the manufacturer's instructions. Complementary DNA (cDNA) was generated with random primers and the target cDNA sequences were amplified by quantitative PCR in a Mx3000P Real-Time PCR System (Applied Biosystems, Foster City, CA, USA). Briefly, total RNA $(1 \mu \mathrm{g})$ was used for each RT reaction. The $20 \mu \mathrm{l} \mathrm{PCR}$ reaction mixture contained $10 \mu \mathrm{l}$ of SYBR Premix, $1 \mu \mathrm{l}$ of each primer and $2 \mu \mathrm{l}$ of cDNA. Sequences of primers were as follows: Forward, 5'-ACCTGAATCACAATCGAGCCA-3' and reverse 5'-TTGGATGCGGATTGTACCCT-3' (thymidylate synthase; TS); Forward, 5'-GGCTATCCTCTCAGA GTGACATTTTA-3' and reverse, 5'-GCTTTATCAGGT TATGTTGCATGGT-3' (excision repair cross-complementing 1;ERCC1); Forward,5'-TCCGGAACCAGTATCGAGAAGA-3' and reverse, 5'-CCTCCTTTTCATTGCCTGCTC-3' (topoisomerase 1; TOPO1); Forward, 5'-GGCTATCCTCTCAGAGT GACTTTTA-3' and reverse, 5'-GCTTTATCAGGTTATGTT GCATGGT-3' (breast cancer susceptibility gene 1; BRCA1); Forward, 5'-CGAGTAAGCATGAAACCAGA-3' and reverse, 5'-CTACTCAAATACGCTTCCCCA-3' (orotate phosphoribosyltransferase; OPRT); Forward, 5'-CCATGGAGAAGGC TGGGG-3' and reverse, 5'-CAAAGTTGTCATGGATGA CC-3' (glyceraldehyde 3-phosphate dehydrogenase; GAPDH). The PCR conditions were $95^{\circ} \mathrm{C}$ for $30 \mathrm{sec}$ followed by 45 cycles at $95^{\circ} \mathrm{C}$ for $5 \mathrm{sec}$ and $60^{\circ} \mathrm{C}$ for $20 \mathrm{sec}$ and, finally, followed by the dissociation curve program $\left(95^{\circ} \mathrm{C}\right.$ for $10 \mathrm{sec}$ at $55-95^{\circ} \mathrm{C}$ with a heating rate of $0.1^{\circ} \mathrm{C} / \mathrm{sec}$ and continuous fluorescence measurement). Relative gene expression quantifications were calculated according to the comparative $\mathrm{Ct}$ method using GAPDH as an endogenous control and cells without cinnamaldehyde treatment as calibrators. Final results were determined by the formula $2^{-\Delta \Delta \mathrm{Ct}}(32)$ and were analyzed with the Stratagene (La Jolla, CA, USA) analysis software.

Statistical methods. Statistical comparisons were performed using the Student's t-test. $\mathrm{P}<0.05$ was considered to indicate a statistically significant difference.

\section{Results}

Cytotoxicity of cinnamaldehyde and chemotherapeutic treatment on LoVo and HT-29 cells. The cytotoxicity of each drug was examined individually in LoVo and HT-29 cell lines. As expected, cinnamaldehyde and each chemotherapeutic agent individually increased the cytotoxicity in the two cell lines in a dose-dependent fashion. Table I displays the $\mathrm{IC}_{50}$ doses for LoVo and HT-29 cell lines following exposure to either cinnamaldehyde or chemotherapeutic agents. The response of LoVo cells to these drugs (except IRI, which is discussed separately below) tended to be weaker than that of HT-29 cells, suggesting that the genetic makeup of cells is important in the response to drug treatment. Next, the obtained $\mathrm{IC}_{50}$ concentrations were used to generate fixed ratios for subsequent combination agent studies and for the calculation of CIs.

Effect of combined cinnamaldehyde and chemotherapeutic treatment on LoVo and HT-29 cells. To explore whether cinnamaldehyde is able to enhance the effects of the chemotherapeutic agents currently used to treat CRC, the effects of $48 \mathrm{~h}$ treatment with cinnamaldehyde, 5-FU and OXA individually and in combination were examined. The combination ratios were designed to approximate the $\mathrm{IC}_{50}$ ratios of the individual agents, so that the contribution of each compound in the combination to the antiproliferative effect was roughly the same (33). Fig. 1 shows the dose-response curves for LoVo (Fig. 1A and B) and HT-29 (Fig. 1C and D) cell lines exposed to cinnamaldehyde and chemotherapeutic agents individually and in combination. For the two cell lines, decreases in cell survival was more pronounced when cells were treated with cinnamaldehyde and chemotherapeutic agents than when only a chemotherapeutic agent was applied. To fully evaluate the nature of the interaction between cinnamaldehyde and chemotherapeutic agents, we analyzed the combination of the two drugs using media effect analysis, which resolves the degree of synergy, additivity, or antagonism. These results are displayed in Fig. 2. We failed to detect the effect of cinnamaldehyde and IRI combination treatment on the two cell lines as IRI therapy had a weak antagonistic relationship (the linear correlation coefficient $>1$ ) and weak reproducibility in the two cell lines.

Apoptotic effects of cinnamaldehyde and chemotherapeutic agents. To test the hypothesis of whether cinnamaldehyde in combination with chemotherapeutic agents is able to increase cell death by inducing apoptosis, flow cytometric analysis was performed. The double staining with Annexin V-FITC and PI was employed to distinguish the apoptotic cells from others. The percentage of early apoptotic cells produced by the treatment with individual chemotherapeutic agents was markedly increased by the presence of cinnamaldehyde, indicating that the simultaneous treatment with cinnamaldehyde and chemotherapeutics induces apoptosis in a synergistic manner (Fig. 3). For example, the percentage of apoptotic (early and late apoptosis) LoVo cells induced by cinnamaldehyde and 5-FU individually was 7.6 and $44.79 \%$, respectively, whereas the percentage induced by the combination of cinnamaldehyde plus 5 -FU was $92.7 \%$.

Effect of cinnamaldehyde on the mRNA expression of drugmetabolizing genes. In an attempt to explain the mechanisms underlying the synergistic interaction between cinnamaldehyde and chemotherapeutic agents, we hypothesized that cinnamaldehyde may affect the expression of chemotherapeutic drug-metabolizing genes (i.e., ERCC1, TS, BRCA1, OPRT and TOPO1) in CRC by affecting its sensitivity to these drugs. Following incubation with cinnamaldehyde and each chemotherapeutic agent individually at their respective $\mathrm{IC}_{50}$ or in combination for $48 \mathrm{~h}, \mathrm{mRNA}$ expression of these 
Table I. $\mathrm{IC}_{50}$ doses for cinnamaldehyde and chemotherapeutic agents.

$$
\mathrm{IC}_{50}(\text { mean } \pm \mathrm{SD} ; \mu \mathrm{g} / \mathrm{ml})
$$

Cell line

\begin{tabular}{llll}
\hline HT-29 & $9.12 \pm 0.46$ & $8.16 \pm 0.30$ & $6.63 \pm 1.86$ \\
LoVo & $9.48 \pm 0.10$ & $2.91 \pm 0.46$ & $7.05 \pm 0.67$ \\
\hline
\end{tabular}

OXA, oxaliplatin; 5-FU, 5-fluorouracil.

A

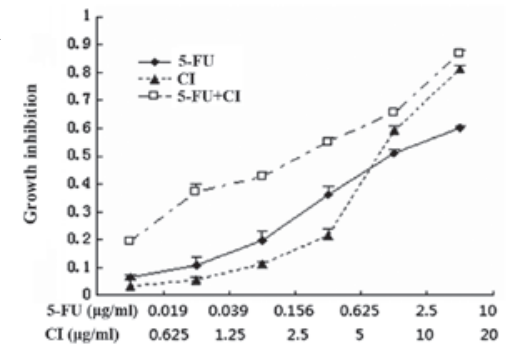

C

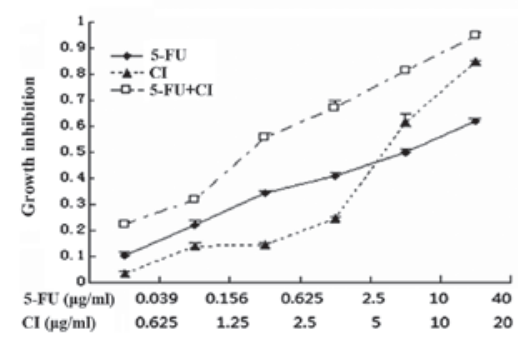

B

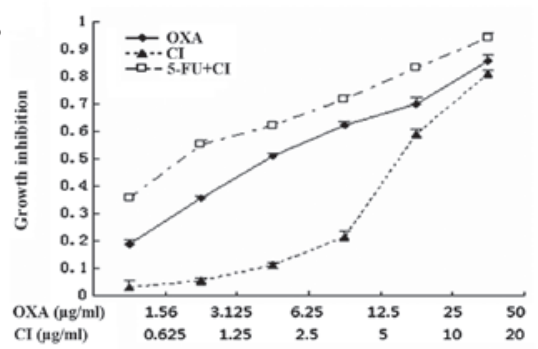

D

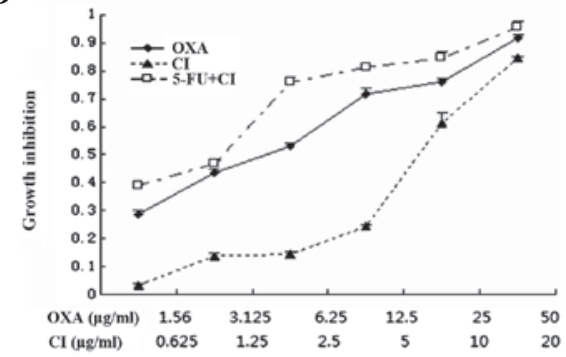

Figure 1. Dose-response curves of cinnamaldehyde and chemotherapeutic agents individually or in combination in (A and B) LoVo and (C and D) HT-29 cells. Each data point represents at least three independent experiments; bars, SD. (A and C), Cinnamaldehyde plus 5-FU; (B and D), cinnamaldehyde plus OXA. 5-FU, 5-fluorouracil; OXA, oxaliplatin; SD, standard deviation.

A

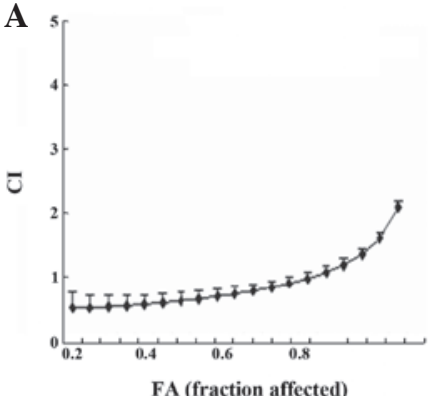

C

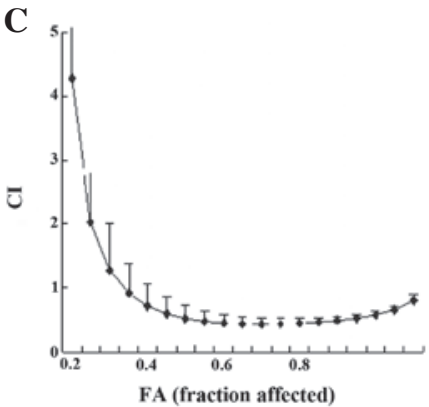

B

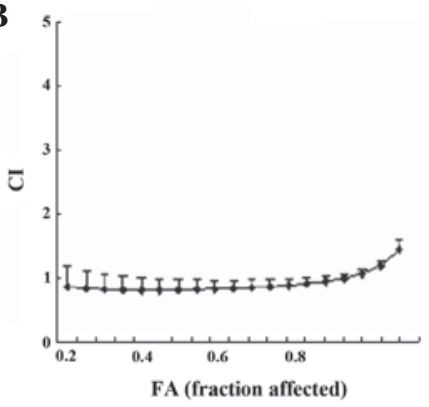

D

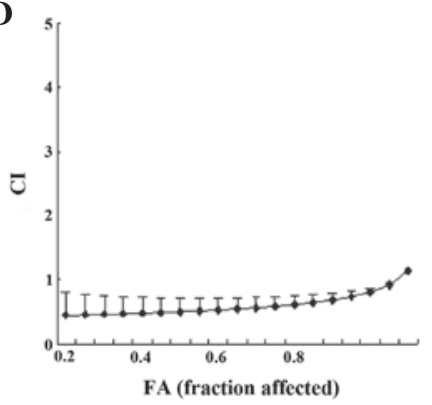

Figure 2. CI values at different levels of growth inhibition effect (FA) in (A and B) LoVo and (C and D) HT-29 cells. Each data point represents at least three independent experiments; bars, SD. (A and C) Cinnamaldehyde plus 5-FU; (B and D), cinnamaldehyde plus OXA. FA, fraction affected; 5-FU, 5-fluorouracil; OXA, oxaliplatin; SD, standard deviation; CI, combination index. 
A

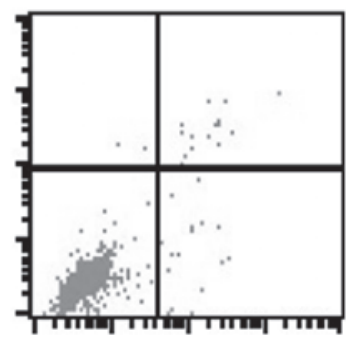

Control

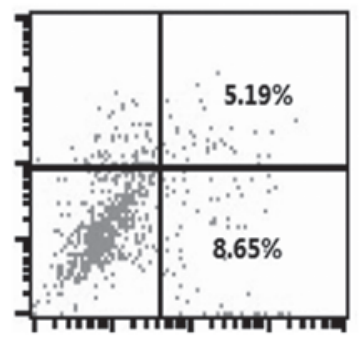

CI $5 \mu \mathrm{g} / \mathrm{ml}$

B
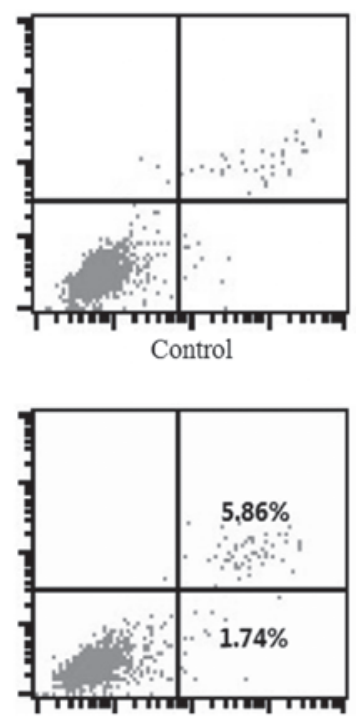

CI $2.5 \mu \mathrm{g} / \mathrm{ml}$

C

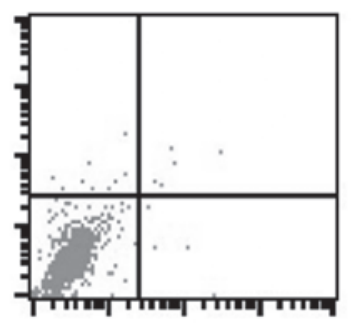

Control

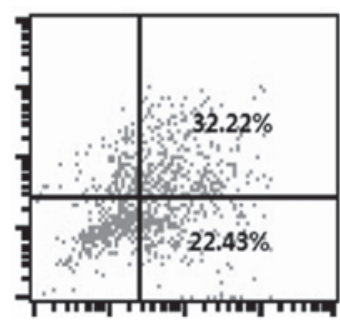

OXA $\quad 6.25 \mu \mathrm{g} / \mathrm{ml}$

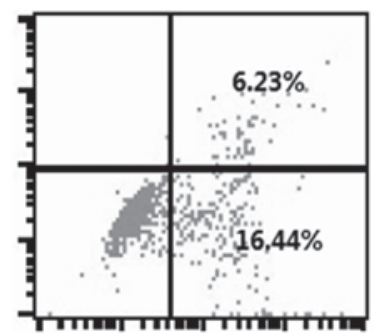

5-FU $0.625 \mu \mathrm{g} / \mathrm{ml}$

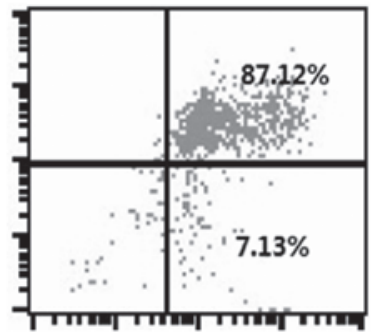

5 -FU +CI

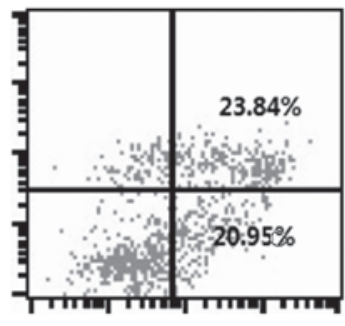

5 -FU $2.5 \mu \mathrm{g} / \mathrm{ml}$

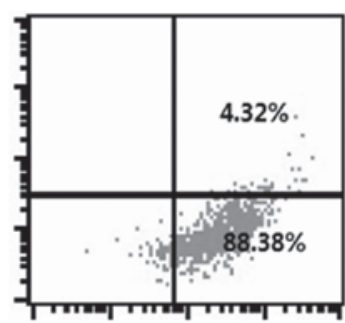

$\mathrm{CI}+5-\mathrm{FU} 2.5 \mu \mathrm{g} / \mathrm{ml}+2.5 \mu \mathrm{g} / \mathrm{ml}$

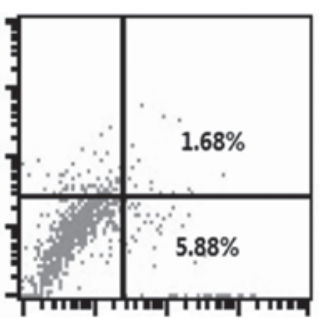

CI $2.5 \mu \mathrm{g} / \mathrm{ml}$

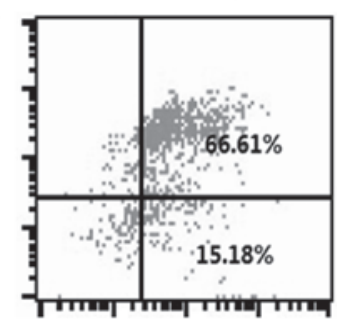

$\mathrm{CI}+$ OXA $2.5 \mu \mathrm{g} / \mathrm{ml}+6.25 \mu \mathrm{g} / \mathrm{ml}$

Figure 3. Annexin V-FITC and PI double staining for apoptosis on (A and B) HT-29 and (C) LoVo 5-FU cells. 5-FU, 5-fluorouracil; PI, phosphatidylserine; OXA, oxaliplatin; CI, combination index.

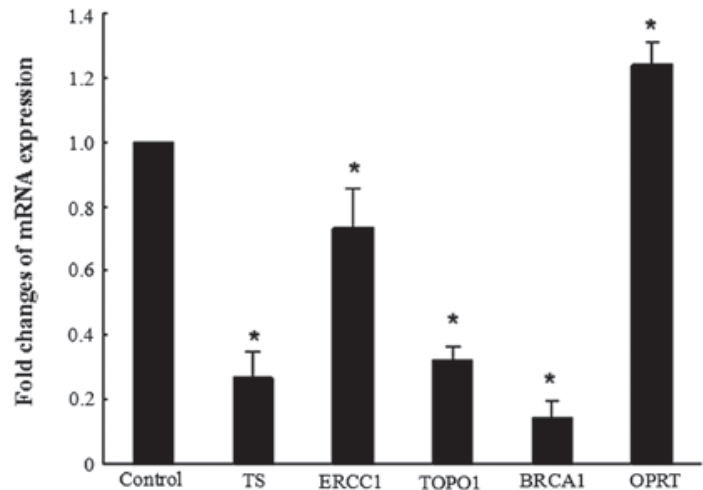

Figure 4. Cinnamaldehyde suppressed the mRNA expression of chemotherapeutic agent-associated genes for HT-29 cells. Fold changes: relative gene expression following treatment of cinnamaldehyde at its $\mathrm{IC}_{50}$ for $48 \mathrm{~h}$ to control. " $\mathrm{P}<0.05$ compared with control. TS, thymidylate synthase; ERCC1, excision repair cross-complementing 1; TOPO1, topoisomerase 1; BRCA1, breast cancer susceptibility gene; OPRT, orotate phosphoribosyltransferase 1 .

genes in HT-29 and LoVo cells was assessed by quantitative RT-PCR.

As displayed in Fig. 4, the expression of ERCC1, TS, BRCA1, and TOPO1 was significantly decreased while the expression of OPRT was significantly increased following the treatment with cinnamaldehyde individually. Furthermore, we also compared the mRNA expression of drug-metabolizing genes in LoVo and HT-29 cells. The results of this analysis showed that TS, BRCA1 and ERCC1 mRNA expression in HT-29 cells was lower while the OPRT mRNA expression was higher in HT-29 cells when compared with the expression of these genes in the LoVo cell line.

\section{Discussion}

Currently, CRC treatment is based on two major new drugs: IRI and OXA. These two chemotherapeutics in combination with 5-FU demonstrate a clear clinical benefit. Nevertheless, the three chemotherapeutic treatments have limited effectiveness due to dosage restrictions as the result of observed toxicity. Numerous plant-derived compounds have been studied for their potential chemopreventive properties and are pharmacologically safe. Recent studies have suggested that these compounds, including genistein, curcumin, emodin, etc., may be used to sensitize tumor cells to chemotherapeutic agents by inhibiting pathways that lead to treatment resistance (17).

The data presented in this study demonstrated a synergistic interaction between cinnamaldehyde and a series of chemotherapeutic agents in two CRC cell lines. Indeed, the positive affect of cinnamaldehyde combination treatment with other drugs was observed previously in human hepatoma PLC/PRF/5 cells in vitro (28). In our study, HT-29 cells were more sensitive to treatment with cinnamaldehyde, 5-FU and OXA as well as their combinations. For its part, LoVo cells also demonstrated synergistic effects of treatment with these drug combinations, however only in certain concentration ranges, while at other concentration ranges an antagonistic effect was observed.

Several previous studies have demonstrated that the effect of antitumor drug combinations may vary depending on the 
tumor cell line tested $(34,35)$. In the present study, a synergistic interaction of cinnamaldehyde and chemotherapeutic agents was observed in two different differentiated CRC cell lines.

Furthermore, we have examined the observed antitumor effect of combined cinnamaldehyde and chemotherapeutic agents at the level of gene expression. Since several drugmetabolizing genes have been demonstrated to be prognostic markers for 5-FU, OXA and IRI CRC therapy, we have decided to examine the effect of cinnamaldehyde addition on their mRNA expression (36-39).

High TS expression level was demonstrated to be associated with the resistance to 5-FU therapy and poor clinical outcome $(36,37)$. Although certain studies have shown opposite results using cancer cell lines or CRC tissue $(40,41)$, a meta-analysis (42) demonstrated that TS expression level was considered to be one of the most important markers of 5-FU response.

In vivo and in vitro studies have demonstrated that OPRT is one of the key enzymes in 5-FU metabolism and its active metabolite phosphorylation is necessary to inhibit cellular DNA synthesis and induce RNA dysfunction (43). In addition, OPRT mRNA expression predicts the sensitivity to 5-FU (i.e., patients with high OPRT expression have a higher sensitivity to 5-FU treatment and are more likely to benefit from it) $(44,45)$.

The cytotoxic effects of platinum agents are principally attributable to the formation of intrastrand adducts leading to DNA damage (25). ERCC1 is a critical element of the DNA repair pathway. High ERCC1 expression is associated with resistance to platinum-containing therapy in human ovarian (46), lung (47) and gastric (38) cancers. ERCC1 has been demonstrated to be an independent prognostic marker of platinum-based chemotherapy (48).

The BRCA1 gene is located on human chromosome 17 (17q12-21) and BRCA1 mutations have been associated with the development of breast and ovarian cancers (40). In addition, BRCA1 expression was associated with the efficacy of platinum and anti-microtubule chemotherapy (39). Indeed, high BRCA1 expression was observed in tumor cells sensitive to taxane, while low BRCA1 expression was present in tumor cells sensitive to platinum-based drug treatment $(49,50)$.

IRI is a semi-synthetic soluble camptothecin derivative and acts as a specific inhibitor of TOPO1. Specifically, IRI acts in the S-phase (synthesis) of the cell cycle and forms a stable binding complex of TOPO1 and DNA causing long DNA strand breaks in cell replication which, in turn, leads to irreversible DNA damage and the death of tumor cells (51).

In the present study, we demonstrated that TS, ERCC1, TOPO1 and BRCA1 were downregulated, however OPRT was upregulated in the presence of cinnamaldehyde, suggesting that it may sensitize tumor cells to 5-FU and OXA therapy.

We have examined the apoptotic effects of cinnamaldehyde and chemotherapeutic agents on two CRC cell lines, individually and in combination, to determine whether the observed synergistic antiproliferative effects of the drugs is due to their synergistic effects on apoptosis. Indeed, the results of the apoptosis analysis indicated that cinnamaldehyde appears to be a promising candidate for combination treatment with anticancer drugs, particularly 5-FU and OXA. Nevertheless, the combined treatment with cinnamaldehyde and IRI had antagonistic effects.
These drugs induced DNA damage directly or indirectly (52) and the cell death was predominantly induced via the p53-dependent pathway (53). On the other hand, several studies have demonstrated that cinnamaldehyde induces apoptosis in tumor cells through the activation of the pro-apoptotic B-cell lymphoma 2 family proteins and mitogen-activated protein kinase pathway (54). Another study proposed that cinnamaldehyde induces tumor cell death through the inhibition of $\mathrm{NF}-\kappa \mathrm{B}$ and AP1 (55). Therefore, the pathway induced by cinnamaldehyde leading to apoptosis may be complementary to that induced by chemotherapeutic agents. This may explain at least in part the synergistic effects of cinnamaldehyde in combination treatment with these drugs. Nevertheless, this hypothesis needs to be further explored by additional studies.

The quantitative determination of synergism or antagonism alone does not provide information regarding how and why synergism or antagonism occurs. Therefore, further studies investigating how cinnamaldehyde affects the expression of drug-metabolizing genes need to be conducted.

In conclusion, to the best of our knowledge, this study is the first to demonstrate that cinnamaldehyde may have a promising role in enhancing the efficacy of either 5-FU or OXA treatment of human CRC. The underlying potential mechanism of action may be through their synergistic effects on apoptosis and the downregulation of chemotherapeutic agent-associated genes. Furthermore, preclinical and clinical studies should provide additional insights and assist in determining the optimal dose and schedule for this combination in clinical use. Nevertheless, it is clear that cinnamaldehyde holds considerable promise as an adjuvant to conventional chemotherapy.

\section{Acknowledgements}

This project was funded by the Priority Academic Program Development of Jiangsu Higher Education Institutions.

\section{References}

1. Ferlay J, Autier P, Boniol M, Heanue M, Colombet M and Boyle P: Estimates of the cancer incidence and mortality in Europe in 2006. Ann Oncol 18: 581-592, 2007.

2. Jemal A, Siegel R, Ward E, Hao Y, Xu J and Thun MJ: Cancer statistics, 2009. CA Cancer J Clin 59: 225-249, 2009.

3. Parkin DM, Bray F, Ferlay J and Pisani P: Global cancer statistics, 2002. CA Cancer J Clin 55: 74-108, 2005.

4. Kamangar F, Dores GM and Anderson WF: Patterns of cancer incidence, mortality, and prevalence across five continents: defining priorities to reduce cancer disparities in different geographic regions of the world. J Clin Oncol 24: 2137-2150, 2006.

5. de Gramont A, Figer A, Seymour M, Homerin M, Hmissi A, Cassidy J, et al: Leucovorin and fluorouracil with or without oxaliplatin as first-line treatment in advanced colorectal cancer. J Clin Oncol 18: 2938-2947, 2000.

6. Douillard JY, Cunningham D, Roth AD, Navarro M, James RD, Karasek P, et al: Irinotecan combined with fluorouracil compared with fluorouracil alone as first-line treatment for metastatic colorectal cancer: a multicentre randomized trial. Lancet 355: 1041-1047, 2000.

7. Falcone A, Ricci S, Brunetti I, Pfanner E, Allegrini G, Barbara C, et al: Phase III trial of infusional fluorouracil, leucovorin, oxaliplatin, and irinotecan (FOLFOXIRI) compared with infusional fluorouracil, leucovorin, and irinotecan (FOLFIRI) as first-line treatment for metastatic colorectal cancer: the Gruppo Oncologico Nord Ovest. J Clin Oncol 25: 1670-1676, 2007. 
8. Cunningham D, Humblet Y, Siena S, Khayat D, Bleiberg H, Santoro A, et al: Cetuximab monotherapy and cetuximab plus irinotecan in irinotecan-refractory metastatic colorectal cancer. N Engl J Med 351: 337-345, 2004.

9. Hurwitz H, Fehrenbacher L, Novotny W, Cartwright T, Hainsworth J, Heim W, et al: Bevacizumab plus irinotecan, fluorouracil, and leucovorin for metastatic colorectal cancer. N Engl J Med 350: 2335-2342, 2004.

10. Tournigand C, André T, Achille E, Lledo G, Flesh M, Mery-Mignard D, et al: FOLFIRI followed by FOLFOX6 or the reverse sequence in advanced colorectal cancer: a randomized GERCOR study. J Clin Oncol 22: 229-237, 2004.

11. Ocvirk J, Brodowicz T, Wrba F, Ciuleanu TE, Kurteva G, Beslija S, et al: Cetuximab plus FOLFOX6 or FOLFIRI in metastatic colorectal cancer: CECOG trial. World J Gastroenterol 16 : 3133-3143, 2010

12. Bokemeyer C, Bondarenko I, Makhson A, Hartmann JT, Aparicio J, de Braud F, et al: Fluorouracil, leucovorin, and oxaliplatin with and without cetuximab in the first-line treatment of metastatic colorectal cancer. J Clin Oncol 27: 663-671, 2009.

13. Sargent DJ, Wieand HS, Haller DG, Gray R, Benedetti JK, Buyse M, et al: Disease-free survival versus overall survival as a primary endpoint for adjuvant colon cancer studies: individual patient data from 20,898 patients on 18 randomized trials. J Clin Oncol 23: 8664-8670, 2005.

14. Goldberg RM, Rothenberg ML, Van Cutsem E, Benson AB 3rd, Blanke CD, Diasio RB, et al: The continuum of care: a paradigm for the management of metastatic colorectal cancer. Oncologist 12: 38-50, 2007

15. Grothey A, Sugrue MM, Purdie DM, Dong W, Sargent D, Hedrick E, et al: Bevacizumab beyond first progression is associated with prolonged overall survival in metastatic colorectal cancer: results from a large observational cohort study (BRiTE). J Clin Oncol 26: 5326-5334, 2008.

16. Carnaghi $\mathrm{C}$, Zucali $\mathrm{P}$ and Garassino I: Combination of 5-Fluorouracil and folinic acid - is it still the standard therapy for advanced colorectal carcinoma? Tumori 86: S19-S25, 2000.

17. Garg AK, Buchholz TA and Aggarwal BB: Chemosensitization and radiosensitization of tumors by plant polyphenols. Antioxid Redox Signal 7: 1630-1647, 2005.

18. Ahn DK (ed): Illustrated Book of Korean Medicinal Herbs Kyohak Publishing Co. Ltd., Seoul, Republic of Korea, pp562-563, 1998.

19. Koh WS, Yoon SY, Kwon BM, Jeong TC, Nam KS and Han MY Cinnamaldehyde inhibits lymphocyte proliferation and modulates T-cell differentiation. Int J Immunopharmacol 20: 643-660, 1998

20. Bullerman LB, Lieu FY and Seier SA: Inhibition of growth and aflatoxin production by cinnamon and clove oils, cinnamic aldehyde and eugenol, J Food Sci 42: 1107-1109, 1977.

21. Kwon BM, Lee SH, Choi SU, Park SH, Lee CO, Cho YK, et al: Synthesis and in vitro cytotoxicity of cinnamaldehydes to human solid tumor cells. Arch Pharm Res 21: 147-152, 1998

22. Shaughnessy DT, Setzer RW and DeMarini DM: The antimutagenic effect of vanillin and cinnamaldehyde on spontaneous mutation in Salmonella TA104 is due to a reduction in mutations at GC but not AT sites. Mutat Res 480-481: 55-69, 2001.

23. Kwon BM, Lee SH, Cho YK, Bok SH, So SH, Youn MR, et al: Synthesis and biological activity of cinnamaldehydes as angiogenesis inhibitors. Bioorg Med Chem Lett 7: 2473-2476, 1997.

24. Lee CW, Hong DH, Han SB, Park SH, Kim HK and Kwon BM: Inhibition of human tumor growth by 2'-hydroxy- and 2'-benzoyloxycinnamaldehydes. Planta Med 65: 263-266, 1999.

25. Kwon BM, Cho YK, Lee SH, Nam JY, Bok SH, Chun SK Kim JA and Lee IR: 2'-Hydroxycinnamaldehyde from stem bark of Cinnamomum cassia. Planta Med 62: 183-184, 1996.

26. Huang TC, Fu HY, Ho CT, Tan D, Huang YT and Pan MH: Induction of apoptosis by cinnamaldehyde from indigenous cinnamon Cinnamomum osmophloeum Kaneh through reactive oxygen species production, glutathione depletion, and caspase activation in human leukemia K562 cells. Food Chem 103: 434-443, 2007

27. Ka H, Park HJ, Jung HJ, Choi JW, Cho KS, Ha J, et al: Cinnamaldehyde induces apoptosis by ROS-mediated mitochondrial permeability transition in human promyelocytic leukemia HL-60 cells. Cancer Lett 196: 143-152, 2003.

28. Wu SJ, Ng LT and Lin CC: Effects of vitamin E on the cinnamaldehyde-induced apoptotic mechanism in human PLC/PRF/5 cells. Clin Exp Pharmacol Physiol 31: 770-776, 2004.
29. Chew EH, Nagle AA, Zhang Y, Scarmagnani S, Palaniappan P, Bradshaw TD, et al: Cinnamaldehydes inhibit thioredoxin reductase and induce Nrf2: potential candidates for cancer therapy and chemoprevention. Free Radic Biol Med 48: 98-111, 2010.

30. Chou TC and Talalay P: Quantitative analysis of dose-effect relationships: the combined effects of multiple drugs or enzyme inhibitors. Adv Enzyme Regul 22: 27-55, 1984.

31. Mosmann T: Rapid colorimetric assay for cellular growth and survival: application to proliferation and cytotoxicity assays. J Immunol Methods 65: 55-63, 1983.

32. Livak KJ and Schmittgen TD: Analysis of relative gene expression data using real-time quantitative PCR and the 2(-Delta Delta C(T)) Method. Methods 25: 402-408, 2001.

33. Barret JM, Etiévant $C$ and Hill BT: In vitro synergistic effects of vinflunine, a novel fluorinated vinca alkaloid, in combination with other anticancer drugs. Cancer Chemother Pharmacol 45: 471-476, 2000.

34. Kano Y, Akutsu M, Tsunoda S, Mori K, Suzuki K and Adachi KI: In vitro schedule-dependent interaction between paclitaxel and SN-38 (the active metabolite of irinotecan) in human carcinoma cell lines. Cancer Chemother Pharmacol 42: 91-98, 1998.

35. Perez EA and Buckwalter CA: Sequence-dependent cytotoxicity of etoposide and paclitaxel in human breast and lung cancer cell lines. Cancer Chemother Pharmacol 41: 448-452, 1998.

36. Salonga D, Danenberg KD, Johnson M, Metzger R, Groshen S, Tsao-Wei DD, et al: Colorectal tumors responding to 5-fluorouracil have low gene expression levels of dihydropyrimidine dehydrogenase, thymidylate synthase, and thymidine phosphorylase. Clin Cancer Res 6: 1322-1327, 2000.

37. Aschele C, Lonardi S and Monfardini S: Thymidylate Synthase expression as a predictor of clinical response to fluoropyrimidinebased chemotherapy in advanced colorectal cancer. Cancer Treat Rev 28: 27-47, 2002.

38. Metzger R, Leichman CG, Danenberg KD, Danenberg PV, Lenz HJ, Hayashi K, et al: ERCC1 mRNA levels complement thymidylate synthase mRNA levels in predicting response and survival for gastric cancer patients receiving combination cisplatin and fluorouracil chemotherapy. J Clin Oncol 16: 309-316, 1998

39. Miki Y, Swensen J, Shattuck-Eidens D, Futreal PA, Harshman K, Tavtigian S, et al: A strong candidate for the breast and ovarian cancer susceptibility gene BRCA1. Science 266: 66-71, 1994.

40. Grem JL, Danenberg KD, Behan K, Parr A, Young L, Danenberg PV, et al: Thymidine kinase, thymidylate synthase, and dihydropyrimidine dehydrogenase profiles of cell lines of the National cancer Institute's Anticancer Drug Screen. Clin Cancer Res 7: 999-1009, 2001.

41. Nita ME, Tominaga O, Nagawa $H$, Tsuruo $\mathrm{T}$ and Muto T: Dihydropyrimidine dehydrogenase but not thymidylate synthase expression is associated with resistance to 5-fluorouracil in colorectal cancer. Hepatogastroenterology 45: 2117-2122, 1998.

42. Popat S, Matakidou A and Houlston RS: Thymidylate synthase expression and prognosis in colorectal cancer: a systematic review and meta-analysis. J Clin Oncol 22: 529-536, 2004.

43. Su F, Overholtzer M, Besser D and Levine AJ: WISP-1 attenuates p53-mediated apoptosis in response to DNA damage through activation of the Akt kinase. Genes Dev 16: 46-57, 2002.

44. Tian C, Zhou ZG, Meng WJ, Sun XF, Yu YY, Li L, et al: Overexpression of connective tissue growth factor WISP-1 in Chinese primary rectal cancer patients. World J Gastroenterol 13: 3878-3882, 2007.

45. Hashimoto Y, Shindo-Okada N, Tani M, Nagamachi Y, Takeuchi K, et al: Expression of the Elm1 gene, a novel gene of the CCN (connective tissue growth factor, Cyr61/Cef10, and neuroblastoma overexpressed gene) family, suppresses in vivo tumor growth and metastasis of K-1735 murine melanoma cells. J Exp Med 187: 289-296, 1998.

46. Selvakumaran M, Pisarcik DA, Bao R, Yeung AT and Hamilton TC: Enhanced cisplatin cytotoxicity by disturbing the nucleotide excision repair pathway in ovarian cancer cell lines. Cancer Res 63: 1311-1316, 2003

47. Motamed-Khorasani A, Jurisica I, Letarte M, Shaw PA, Parkes RK, Zhang X, et al: Differentially androgen-modulated genes in ovarian epithelial cells from BRCA mutation carriers and control patients predict ovarian cancer survival and disease progression. Oncogene 26: 198-214, 2007. 
48. Sarries C,Haura EB, Roig B, Taron M, Abad A, Scagliotti G, et al: Pharmacogenomic strategies for developing customized chemotherapy in non-small cell lung cancer. Pharmacogenomics 3: 763-780, 2002.

49. Rosell R, Lord RV, Taron M and Reguart N: DNA repair and cisplatin resistance in non-small-cell lung cancer. Lung Cancer 38: 217-227, 2002.

50. Khanna KK and Jackson SP: DNA double-strand breaks: signaling, repair and the cancer connection. Nat Genet 27: 247-254, 2001.

51. Rudolf E, Rudolf K and Cervinka M: Camptothecin induces p53-dependent and -independent apoptogenic signaling in melanoma cells. Apoptosis 16: 1165-1176, 2011.
52. Kaye SB: New antimetabolites in cancer chemotherapy and their clinical impact. Br J Cancer 78 (Suppl 3): 1-7, 1998.

53. Kastan MB, Onyekwere O, Sidransky D, Vogelstein B and Craig RW: Participation of p53 protein in the cellular response to DNA damage. Cancer Res 51: 6304-6311, 1991.

54. Wu SJ, Ng LT and Lin CC: Cinnamaldehyde-induced apoptosis in human PLC/PRF/5 cells through activation of the proapoptotic Bcl-2 family proteins and MAPK pathway. Life Sci 77: 938-951, 2005.

55. Kwon HK, Hwang JS, So JS, Lee CG, Sahoo A, Ryu JH, et al: Cinnamon extract induces tumor cell death through inhibition of NFkappaB and AP1. BMC Cancer 10: 392, 2010. 